\title{
Grand challenges in climate research
}

\author{
Martin Beniston* \\ Institute for Environmental Sciences, University of Geneva, Geneva, Switzerland \\ *Correspondence: martin.beniston@unige.ch \\ Edited by: \\ Luis Gimeno, Universidad de Vigo, Spain \\ Reviewed by: \\ Luis Gimeno, Universidad de Vigo, Spain
}

Keywords: regional climate modeling, cloud processes, sea level rise, cryosphere and climate, communicating on climate issues

\section{INTRODUCTION}

Climate change has been at the forefront of environmental concerns for over a quarter of a century. The sequence of reports published by the Intergovernmental Panel on Climate Change (IPCC, 1990, 1996, 2001, 2007, 2013) has been instrumental in bringing climate issues to the attention of the public and policy-makers alike. In 1992, the United Nations Conference on Environment and Development (UNCED-1992, Rio de Janeiro, Brazil) identified climate change as one of the major environmental challenges facing humankind and the Framework Convention on Climate Change (FCCC) was ratified on this occasion, thereby acknowledging the concerns of governments related to the impacts and risks to environmental resources, local to national economies, and society resulting from a changing climate. The two other major UN conventions drafted at UNCED-1992, namely the biodiversity and the desertification conventions, have never received the attention that the FCCC has, particularly since the Kyoto Protocol, aimed at reducing anthropogenic carbon emissions into the atmosphere, was signed in 1997. Despite much criticism as to the slow pace of negotiations and the limited success in the implementation of the Protocol, it remains to this day a unique attempt to address the greenhouse-gas problem at the global scale.

The issues of climate change have led to heated debates, both within academia as well as between scientists and a large community of skeptics. While the sources of skepticism range from simple denial to organized "anti-global warming" lobbies, the opposition to what is considered to be a consensus view on anthropogenic climate change has had a beneficial side-effect in terms of encouraging improved research and communication. Large efforts have been deployed to improve the knowledge base on the functioning of the climate system, observations of the Earth system, numerical modeling techniques, and data handling and analysis.

Despite large scientific progress in the last two decades, many domains of uncertainty still remain as to the functioning of the climate system. The reduction of these uncertainties would be unlikely to radically change the fairly robust conclusion that contemporary climate change is to a significant degree driven by anthropogenic emissions of greenhouse gases. However, furthering our understanding of climaterelevant processes would improve not only the predictive capability of climate models at space and time scales useful to decisionmaking, but also help reduce criticisms when communicating on climate issues.

The outstanding issues that need continued scientific focus are today collectively termed as "grand challenges," since many of these issues have been addressed over many years by many research teams, but still have large uncertainties associated with them. The World Climate Research Program (WCRP), one of the flagship domains of the World Meteorological Organization (WMO) has identified a number of these challenges that are currently receiving enhanced scientific attention that will be outlined in the next section. Indeed, the CLIVAR (Climate predictability and variability) program of the WCRP has proposed the definition that "A Grand Challenge is both highly specific and highly focused identifying a specific barrier preventing progress in a critical area of climate science." In addition to the fundamental science issues identified by the WCRP, two further issues are identified as grand challenges in this paper, namely those associated improved communication of science, and those linked to access to environmental and socioeconomic data for research purposes.

\section{GRAND CHALLENGES IN THE PHYSICAL ASPECTS OF CLIMATE}

The current state of knowledge of the climate system and its functioning contains a range of uncertainties inherent to most complex non-linear systems. These need to be further addressed by the research community in order to enhance the confidence in the understanding and prediction of the system (Asrar and Hurrell, 2013). The outstanding areas identified by the WCRP as "grand challenges" requiring particular attention, are briefly outlined below.

\section{SEA-LEVEL RISE}

The potential impacts of sea-level rise on coastal cities through permanent flooding or greater vulnerability to storm surges, as well as on the increasing risks of salt intrusion into ground water and the collateral effects on the fertility of agricultural soils, for example, have been widely reported in the IPCC (2007) reports. While earlier assessments of sea-level rise as a function of a warming climate seemed to be fairly robust, there is today much greater uncertainty; current estimates of sea-level rise range from $20 \mathrm{~cm}$ by 2100 (Meehl et al., 2007) to $2 \mathrm{~m}$ or more (Vermeer and Rahmstorf, 2009). One of the principal reasons for this increased uncertainty in sea-level projections is related to the behavior of the Greenland ice sheet that has been showing signs of accelerated melting and calving at a scale that was unanticipated a decade ago. Ocean processes linked to the thermohaline circulation and the contribution of modes of climate variability such as the North Atlantic Oscillation require further 
understanding in order to enable more refined estimates of changes in sea-level at the regional scale and thereby to prepare for appropriate adaptation strategies.

\section{CRYOSPHERIC PROCESSES}

The major changes currently observed notably on the Arctic sea-ice and on the Greenland ice sheet are part of a twoway interaction between climate and the high-latitude cryosphere that can lead to amplification of warming and higher rates of sea-level rise than hitherto anticipated. Permafrost beneath large ice-sheets could increasingly melt as surface waters infiltrate to the base of the ice sheet. As the permafrost recedes, melt-waters could enter into porous bedrock regions that would reduce the amount of water flowing into the oceans, and thereby confound gravitybased estimates of the contribution of ice melting to sea-level rise. Thawing permafrost in the continental areas bordering the Arctic Ocean is also likely to contribute additional amounts of carbon into the atmosphere, with a probable amplification of the greenhouse effect. These mechanisms require more refined quantification in order to enable models to assess the response of climate to this additional perturbation to the global carbon cycle.

\section{THE ROLE OF CLOUDS AND AEROSOLS IN THE CLIMATE SYSTEM}

The aggregate role of clouds in the climate system remains probably one of the largest sources of uncertainty in climate models and thus for reliable projections of climate change. The limited performance of climate models to accurately represent cloud processes is related to both the coarse resolution of model grids that do not normally resolve individual clouds, and to the high level of parameterization required to account for the thermodynamic and radiative influence of clouds on their atmospheric environment. Because clouds are a major modulator of heat processes in the atmosphere, this particular area of climate-relevant grand challenges requires in-depth attention as to the coupling of clouds and atmospheric circulations under current climate, and their response to greenhouse-gas forcing. Of particular interest is the manner in which clouds may amplify or dampen climate warming through their role in the radiation budget of the globe. A further set of issues linked to clouds relates to the observation and modeling of precipitation. Precipitation and its geographical patterns influence not only surface waters but also soil moisture that in turn can induce important feedback mechanisms leading in some instances to the amplification of heat wave events, for example (e.g., Seneviratne et al., 2006). The accurate measurement of precipitation and its spatial extent is a key to improved modeling of processes highly-relevant to climate. The role of aerosols in the climate system is better understood today than a decade or two ago, but there are still large areas of uncertainty related to the influence of the ocean in terms of aerosol release into the atmosphere (e.g., Spada et al., 2013).

\section{WATER AVAILABILITY}

Changes in the polar cryosphere and mountain glaciers are impacting water availability and as a consequence the economic sectors that require water at critical periods of the year (e.g., hydropower, agriculture, tourism). In many mountain regions, changes in cryospheric processes are among the greatest modulators of hydrological systems, both within the mountains themselves and far downstream. Additional research foci aim at a better understanding the environmental and socio-economic impacts of changing seasonality, quantity, and quality of water. However, the detailed projections required at regional to local scales (see Section Access to Data for Climate Research below) are still sparse and do not always enable to convey the type of information required by decision makers, particularly in regions that are geographically-remote and with sparse data availability. This kind of high-resolution information is necessary to implement appropriate adaptation strategies, in particular improved water governance in order to avoid conflicts of interest over water use among different economic sectors (e.g., Beniston et al., 2011).

\section{LINKING EXTREME EVENTS TO CLIMATE CHANGE}

Extreme events represent the most costly climate-related features in human and economic terms, and reinsurance statistics (e.g., EEA, 2012) suggest that more than
$80 \%$ of total damage costs and $95 \%$ of insured costs in Europe are related to weather and climate (storms, heat and cold waves, droughts and floods), the remainder of these costs being linked to geophysical hazards such as earthquakes. While some of these damages can be attributed to the weather elements themselves, many of the costs are related to the fact that there is an increase in population pressures in regions that are at risk. There is thus a clear incentive to undertake focused research to see whether the intensity and/or the frequency of extremes has changed in recent decades, and thus to determine possible causeto-effect relationships between long-term climate trends and severe events. In particular, regions now relatively unaffected by catastrophic events could become vulnerable in the future, with associated damage costs that could be extremely high. Climate models at high spatial resolution are today capable of reproducing certain extremes, but the causal mechanisms underlying these phenomena require further investigation in order to assess whether they are affected by long-term mean changes in climate (e.g., Peterson et al., 2012).

\section{ACCESS TO DATA FOR CLIMATE RESEARCH}

Data for climate research is in many instances difficult to access, often at a price, and according to the source and type of data, the formats for retrieval can be very different. In addition, data may not be available for the same time and spacescales. There is often an incompatibility between socio-economic and physical data, both necessary for climate modeling efforts, because data collection is generally carried out by different agencies for different purposes. Although often overshadowed by problems of a purely scientific nature, those related to data access often represent a bottleneck in climate research. Future efforts should thus focus on compatible data sets including their formats. Improved data handling should also include methodological software that can enable scale changes (e.g., downscaling from regional to local spatial entities) and bias correction of the data. Beyond access to data, there is also the need to better assimilate satellite data, for example, for an improved understanding of clouds, aerosols, cryospheric processes, and to 
enhance the rather sparse ocean data in order to characterize three-dimensional ocean dynamics.

\section{REGIONAL CLIMATE INFORMATION}

For appropriate decision-making in terms of climate adaptation and mitigation, model results at high spatial and temporal resolution are of the essence. While the grid-spacing in global climate models has been steadily increasing over time, much of the information from global models remains too coarse for most endusers. The pioneering work of Giorgi and Mearns (1991) in terms of nested global-to-regional modeling techniques has proven useful for climate studies requiring high-resolution techniques; the coupled model approach has the advantage of being physically-based, but on the other hand is highly dependent on the initial and boundary conditions provided by the global models that drive their regional counterparts (i.e., any errors from a global model would propagate into the regional model domains and contaminate their results). Beyond the need for high resolution, regional climate models ultimately need to provide projections on climate variability from seasonal, through decadal to century time scales. In order to achieve this goal, models need to continuously upgrade their performance through the incorporation of the latest knowledge on physical and chemical processes and feedback mechanisms (e.g., clouds and aerosols with the atmosphere, oceanatmosphere coupling, cryosphere-oceanatmosphere feedbacks, etc.).

\section{GRAND CHALLENGES IN COMMUNICATING CLIMATE SCIENCE}

Although there has been a wealth of media attention dedicated to climate issues since the early 1990s, the media have also been instrumental in bringing the viewpoints of controversial science and climate skepticism to the forefront of public attention. Climate skeptics range from a science-wary public who find it difficult to believe that a community of individuals can actually influence a massive "planetary machine," to more organized lobbies that have vested interests in shedding doubt on the possible human influence on climate (e.g., Oreskes and Conway, 2010). The authors show how groups of high-level advisors with strong links to influential political and industrial spheres, established campaigns aimed at discrediting scientific knowledge in the eyes of the public. Since the second half of the twentieth century, lobbies often composed of the same individuals have attacked the idea of anthropogenic global warming along the same lines as they attempted to deny the links between smoking and cancer, the human factor in the ozone depletion problematic, and the links between coal combustion and acid rain, to name but a few issues-with far-reaching economic implications - that have surfaced in the post-Second World War decades.

Skepticism with respect to scientific issues raises the question of whether the scientific community is capable not only of communicating science in a manner accessible to a non-expert audience, but also of doing so in a manner sufficiently convincing in order to defuse the arguments from a skeptical audience. Indeed, most researchers are trained in their domains of expertise and are not necessarily geared to make their case outside of the implicit boundaries of academic science. Climatic change in particular can be a difficult concept to convey to a non-expert audience; many of the results on current or future climates are based on temperature change with respect to a particular baseline climate, for example the generally-accepted temperature increase of $0.7^{\circ} \mathrm{C}$ since 1900 (e.g., IPCC, 2007). For a lay audience, this kind of statistic is difficult to interpret, and for many persons would seem to be a small, even insignificant figure. The concept of a changing climate can in some instances be easier to grasp when identifying visible impacts of a climate that has evolved significantly in certain regions of the globe. One example would typically be that of the retreat of mountain glaciers that is very much present in most mountain regions, and can be easily conveyed through photographs taken over a number of decades or even years. More recently, socalled climate analogs have been used as a means of showing the extent of change that has intervened over a matter of just a few decades. Hallegatte et al. (2007) were among the first to use geographical analogs to show how impacts in a future climate in one part of Europe would resemble those in other parts of Europe in today's climate.
More recently, Beniston (in press) has used the analog method to show that in Europe, temperature regimes have moved northwards by $500-600 \mathrm{~km}$ within half a century or less. For example, it is possible to show through joint temperature and precipitation statistics that the climate of Geneva in the 2010s is similar to that of Toulouse in the 1960s; and that of Toulouse today is close to that of Madrid in the middle of the Twentieth century. Although analog methods have their limitations, they do have merit in translating the more abstract notion of temperature change over time into a statistic that can be more readily understood by a lay audience.

Climate science communication represents a challenge that should not be taken lightly, and despite the care taken in preparing reports such as those of the IPCC-including the widely-read "Summary for Policy Makers"-there is still a large gap between the messages that the science community wishes to transmit and those that the end-recipients are willing or capable of receiving. It is increasingly necessary to communicate clearly not only on the current state of knowledge on climatic change and climate impacts issues, but also to clearly justify why uncertainty exists in complex systems-and why decisionmaking is nevertheless possible despite these uncertainties. Communicating on climate should also include robust explanations on the vulnerability of systems impacted by climate, the potential impacts of a changing climate on a range of social and economic systems, and ethical and legal issues pertaining to joint and differentiated responsibility for climate impacts.

\section{CONCLUDING REMARKS}

A number of "grand challenges" in climate science have been outlined here, in order to highlight some of the key issues that require further in-depth investigations to enable improved understanding of the complexities of the climate system and greater confidence in the predictive capabilities of climate models. In a world where policy needs are focused on the local to regional scales, reducing current uncertainties in climate science faces is an essential key to improved sciencepolicy dialogs. Furthering our knowledge 
by addressing these grand challenges will also enable greater confidence in the analysis of climate impacts on a range of natural systems (e.g., ecosystems, water, snow and ice) and socio-economic systems (e.g., energy supply and demand, agriculture, insurance and finance, etc.). To quote from a white paper published in 2012 by the WCRP, addressing "grand challenges" in climate should be aimed at "enabling the development of targeted research efforts with the likelihood of significant progress over 5-10 years even if its ultimate success is uncertain [... and to ...] enable the implementation of effective and measurable performance metrics."

\section{REFERENCES}

Asrar, G. R., and Hurrell, J. W. (eds.) (2013). Climate Science for Serving Society: Research, Modeling and Prediction Priorities. Dordrecht: Springer SBM, 459. doi: 10.1007/978-94-0076692-1

Beniston, M. (in press). European isotherms move northwards by up to $15 \mathrm{~km} /$ year: using climate analogues for awareness-raising. Int. J. Climatol. doi: $10.1002 /$ joc.3804

Beniston, M., Stoffel, M., and Hill, M. (2011). Impacts of climatic change on water and natural hazards in the Alps: can current water governance cope with future challenges? Examples from the European "ACQWA" project. Environ. Sci. Policy 14, 734-743. doi: 10.1016/j.envsci.2010.12.009

EEA (European Environment Agency), (2012). "Damages from weather and climate-related events," in CLIM-039 report of the EEA, (Copenhagen). Available online at: http://www. eea.europa.eu/data-and-maps/indicators/direct-lo sses-from-weather-disasters-1/assessment

Giorgi, F., and Mearns, L. O. (1991). Approaches to the simulation of regional climate change: a review. Rev. Geophys. 29, 191-216. doi: 10.1029/90RG02636

Hallegatte, S., Hourcade, J. C., and Ambrosi, P. (2007). Using climate analogues for assessing climate change economic impacts in urban areas. Clim. Change 82, 47-60. doi: 10.1007/s10584-0069161-z

IPCC, (1990). Climate Change: The Assessment Reports of the Intergovernmental Pane on Climate Change. Cambridge, UK: Cambridge University Press.

IPCC, (1996). Climate Change: The Assessment Reports of the Intergovernmental Pane on Climate Change. Cambridge, UK: Cambridge University Press.

IPCC, (2001). Climate Change: The Assessment Reports of the Intergovernmental Pane on Climate Change. Cambridge, UK: Cambridge University Press.

IPCC, (2007). Climate Change: The Assessment Reports of the Intergovernmental Pane on Climate Change. Cambridge, UK: Cambridge University Press.

IPCC, (2013). Climate Change: The Assessment Reports of the Intergovernmental Pane on Climate Change. Cambridge, UK: Cambridge University Press.

Meehl, G. A., Stocker, T. F., Collins, W. D., Friedlingstein, P., Gaye, A. T., Gregory, J. M. et al. (2007). "Global climate projections," in Climate Change: The Physical Science Basis, eds S. Solomon, D. Qin, M. Manning, Z. Chen, M. Marquis, K. B. Averyt et al. (Cambridge, UK: Cambridge Universtiy Press), 749-845.

Oreskes, N., and Conway, E. M. (2010). Merchants of Doubt. New York; London: Bloomsbury Press, 355.
Peterson, T. C., Stott, P. A., and Herring, S. (2012). Explaining extreme events of 2011 from a climate perspective. Bull. Am. Meteorol. Soc. 93, 1041-1067. doi: 10.1175/BAMS-D-12-00021.1

Seneviratne, S. I., Lüthi, D., Listchi, M., and Schaer, C. (2006). Land-atmosphere coupling and climate change in Europe. Nature 443, 205-209. doi: 10.1038/nature05095

Spada, M., Jorba, O., Perez, C., Janjic, Z., and Baldasano, J. M. (2013). Modeling and evaluation of the global sea-salt aerosol distribution: sensitivity to emission schemes and resolution emission schemes and resolution effects at coastal/orographic sites. Atmos. Chem. Phys. Discuss. 13, 11597-11657. doi: 10.5194/acpd-1311597-2013

Vermeer, M., and Rahmstorf, S. (2009). Global sea level linked to global temperatures. Proc. Natl Acad. Sci. U.S.A. 106, 21527-21532. doi: 10.1073/pnas.0907765106

Received: 25 September 2013; accepted: 01 October 2013; published online: 25 October 2013.

Citation: Beniston M (2013) Grand challenges in climate research. Front. Environ. Sci. 1:1. doi: 10.3389/ fenvs.2013.00001

This article was submitted to Interdisciplinary Climate Studies, a section of the journal Frontiers in Environmental Science.

Copyright (c) 2013 Beniston. This is an open-access article distributed under the terms of the Creative Commons Attribution License (CC BY). The use, distribution or reproduction in other forums is permitted, provided the original author(s) or licensor are credited and that the original publication in this journal is cited, in accordance with accepted academic practice. No use, distribution or reproduction is permitted which does not comply with these terms. 